\title{
Effect of melting pressure and superheating on chemical composition and contamination of yttria-coated ceramic crucible induction melted titanium alloys
}

\author{
F. Gomes $\cdot$ H. Puga $\cdot$ Joaquim Barbosa $\cdot$ \\ C. Silva Ribeiro
}

Received: 14 June 2010/Accepted: 15 February 2011/Published online: 26 February 2011

(C) Springer Science+Business Media, LLC 2011

\begin{abstract}
When melting reactive alloys, chemical composition and alloy homogeneity strongly depend on processing conditions, especially if melting is performed in ceramic crucibles. In this case, the nature of crucible materials, the melting stock composition and the melting parameters (atmosphere, pressure, superheating time and temperature) are critical processing variables. In this work, a $\mathrm{Ti}-48 \mathrm{Al}$ alloy was induction melted in a $\mathrm{ZrO}_{2} \cdot \mathrm{SiO}_{2}$-based crucible with $\mathrm{Y}_{2} \mathrm{O}_{3}$ inner layer using different superheating temperatures $\left(1600\right.$ and $\left.1650{ }^{\circ} \mathrm{C}\right)$ and times $(0,60$ and $90 \mathrm{~s})$ and poured into a graphite mould. The influence of different temperature/time combinations in the alloy composition, Al loss by evaporation and metal/crucible interaction was studied for different melting pressures. Al loss was found to increase significantly for melting pressures below $10^{-2}$ mbar and increases with increasing superheating time and temperature. The experimental results concerning to $\mathrm{Al}$ loss are in agreement with theoretical (and experimentally validated) models available for induction skull melting of TiAl. Metal/crucible interaction directly increased with melting pressure, superheating time and temperature, leading to alloy contamination with $\mathrm{Y}$ and $\mathrm{O}$. For the experimental set-up used in this work, optimal temperature/superheating time/pressure combinations that lead to acceptable alloy composition have been identified.
\end{abstract}

F. Gomes $\cdot$ H. Puga $\cdot$ J. Barbosa $(\bowtie)$

Departamento de Engenharia Mecânica, Universidade do Minho, 4800-058 Guimarães, Portugal

e-mail: kim@dem.uminho.pt

C. S. Ribeiro

Departamento de Engenharia Metalúrgica e Materiais,

FEUP, 4100 Porto, Portugal

\section{Introduction}

The industrial interest of titanium parts

The development of the automotive industry strongly depends on two main issues: increased fuel-efficiency to reduce gas emissions and improved automobile performance [1]. To achieve such goals, the use of advanced materials to improve the quality of car components and significant weight reduction are crucial $[2,3]$, both for traditional propulsion systems and, particularly, for future generation of hybrid cars.

To reduce fuel consumption, a significant weight decrease of the moving mass of the engine-pistons, valve trains and turbine wheels of turbochargers-is necessary $[4,5]$. Moreover, the use of lighter valve trains will have to be followed by a change in the combustion regime of the car engine, which will increase the exhaust gas temperatures from currently $600{ }^{\circ} \mathrm{C}$ to around $800{ }^{\circ} \mathrm{C}[2,3]$. In such conditions, traditional steel grades and superalloys currently used in valve and turbocharger wheels will no longer be suitable, and TiAl-based alloys are the most serious candidates to replace them [6, 7]. Car manufacturers are already using these alloys in exhaust valves (Toyota, Nissan and Chevrolet) [8] and turbocharger wheels (Mitsubishi and Daimler) $[6,8]$ in top models and racing cars.

Porsche, Ferrari, Honda and Volkswagen have been introducing other Ti-based components in series production models (connection rods, exhaust systems and suspension springs) [8], which reveals the interest of the automotive industry on this subject.

Besides the automotive industry, TiAl alloys will soon be introduced in GE commercial aeroengines [9] and are already in use in military equipment (P\&W F119 engine of 
the F22 aircraft, LW155 Cannon, etc.) [10], while traditional $\mathrm{Ti}$ alloys are finding application in sports equipment and biomechanics.

At the present stage, the main factors limiting the manufacture of mass market TiAl-based components are the intrinsic characteristics of TiAl alloys-microstructure and chemical heterogeneity, brittleness, low room temperature ductility and poor hot workability [11], and the high production costs. Present production routes of TiAl components are limited to forging and rolling, powder metallurgy and casting. The first two are very prone to chemical and microstructure heterogeneity, usually have low yield and lead to dimensional/geometrical inaccuracy, making machining unavoidable, which can be extremely expensive because of the poor machinability of these alloys. Powder metallurgy is highly expensive and limited to simple geometries. Casting is the most versatile technique to process $\mathrm{TiAl}$; however, the high reactivity of Ti-based alloys in the molten state makes it difficult to use traditional foundry techniques to produce high quality parts.

Therefore, the development of a reliable casting technique capable of producing near net shape castings without contamination, at a competitive price, has been a key issue for many foundry researchers and presently some techniques are available but all of them present some sort of drawbacks.

\section{Casting of titanium-based parts}

\section{Current casting techniques}

Titanium alloys present very low fluidity at pouring temperatures, requiring a significant amount of superheating in order to avoid misrun and cold laps in the cast parts [12]. On the other hand, titanium castings are usually complexshaped parts with thin walls, in order to be as light as possible, which require high metal pouring temperature and/or high mould preheat temperature. So far, research on this field revealed that the use of low superheating temperatures and high mould preheat temperatures, associated with pressure assisted pouring, like centrifugal pouring, is usually the best solution to avoid simultaneously casting defects like misrun and cold laps, metal chemical contamination and solidification defects like shrinkage [12-14].

Induction skull melting (ISM) (the process uses a water cooled copper crucible where the first molten metal immediately solidifies forming a protective layer of metal at the crucible walls) combined with the investment casting moulding process is the most used technique to cast titanium-based parts. However, ISM has a high impact in the castings final cost and generates high levels of rejections, mainly due to the difficulty to reach suitable superheating. To overcome this problem, excessively high mould preheat temperatures are frequently used, thus increasing the probability of a metal-mould reaction occurring leading to metal contamination and development of solidification defects. Moreover, pouring is usually very rapid and turbulent causing gas entrapment in the solidified casting, in the shape of bubbles, or even the formation of oxide films [15]. The current solution to overcome such drawbacks is to increase the section thickness of the castings for subsequent machining, but this solution adds further costs and eliminates the potential benefits of near net shape casting [16].

The use of traditional ceramic crucibles to melt titanium alloys is not an easy task, due to the high reactivity of the molten alloys with ceramic materials. Attempts to identify a suitable ceramic material that might be used in crucibles and/or mould production started some decades ago. A review article of Frueh [17] published in 1996 revealed that different oxides, carbides, borides and sulphides have been studied and evaluated, but results in general were unsatisfactory, and most of those materials have been considered inappropriate to process Ti-based alloys. Nevertheless, Frueh refers to some good results concerning to metal contamination by using $\mathrm{ZrO}_{2}$ and $\mathrm{Y}_{2} \mathrm{O}_{3}$, but refers the low thermal shock resistance of those materials as a major limitation to its use in crucible production. More recently, Liu et al. [18] have studied the reactivity of $\mathrm{Y}_{2} \mathrm{O}_{3}, \mathrm{Y}_{2} \mathrm{O}_{3}$ and $\mathrm{MgO}$ stabilized $\mathrm{ZrO}_{2}$ and zircon sand against a Ti-Al$\mathrm{Cr}-\mathrm{Nb}$ alloy by means of differential thermal analysis and scanning electron microscopy and found that with exception to $\mathrm{Y}_{2} \mathrm{O}_{3}$ (which slightly reacted with the Ti alloy) every other refractory reacted significantly. Nevertheless, considering the high cost of $\mathrm{Y}_{2} \mathrm{O}_{3}$ those researchers considered the ratio performance/cost of $\mathrm{Y}_{2} \mathrm{O}_{3}$ stabilized $\mathrm{ZrO}_{2}$ the best option for crucible/mould production.

Some researchers claim to have successfully melt titanium alloys in $\mathrm{CaO}$ crucibles at lab [19] and industrial scales $[20,21]$. Although $\mathrm{CaO}$ presents the lowest free Gibbs energy of formation among every metallic oxide with exception to $\mathrm{Y}_{2} \mathrm{O}_{3}$, researchers refer a slight contamination of the alloys with oxygen and the presence of non-metallic inclusions. Moreover, the high hygroscopicity of $\mathrm{CaO}$ makes difficult its generalized use in industrial environment.

Other researchers have focused their attention in nonoxide refractories to develop a crucible material for melting Ti-based alloys. Kartavykh and other researchers have recently characterized the metal-mould interaction between TiAlNb melts and Pyrolytic BN [22] and AlN [23] crucibles. BN crucibles reacted severely with TiAlNb, leading to the formation of a complex reaction layer that 
propagates quickly towards the alloy. AlN crucibles performed quite well, leading to the formation of a few microns thick TiN-based reaction layer that promoted good wetting ability of the crucible with the melt, preventing the presence of non-metallic inclusions in the alloy matrix. Moreover, this reaction layer could be easily removed by sand blasting or traditional machining of the casting.

During the last decade, some of the authors developed extensive research on this field, and $\mathrm{ZrO}_{2}$ and $\mathrm{ZrO}_{2} \cdot \mathrm{SiO}_{2^{-}}$ based crucibles with inner $\mathrm{Y}_{2} \mathrm{O}_{3}$ layer (which has the lowest Gibbs energy of formation the most stable metallic oxide) have been developed and patented [24, 25]. Melts conducted in those $\mathrm{ZrO}_{2}+\mathrm{Y}_{2} \mathrm{O}_{3}$ crucibles revealed the lowest oxygen contamination referred so far for ceramic crucible melting of TiAl ( $0.08 \mathrm{wt} \%$ oxygen increase after $90 \mathrm{~s}$ at $1875 \mathrm{~K}$ ) [26], but the presence of small inclusions of $\mathrm{Y}_{2} \mathrm{O}_{3}$ in the metal matrix have not been avoided yet.

Mould materials also play an important role on the overall quality and final cost of Ti-based parts. Suitable refractory materials, inert facing $\mathrm{Ti}$ alloys, have to be used in order to avoid surface contamination and development of the so called alpha-case which elimination requires high costly special machining or chemical milling operations. Nevertheless, there is evidence that "alpha-case" can be reduced to a minimal acceptable level or even eliminated if $\mathrm{Y}_{2} \mathrm{O}_{3}$ [27, 28] or $\mathrm{Al}_{2} \mathrm{O}_{3}$ [29] are used as face coats in investment casting shells.

Thus, considering the actual panorama of Ti alloys processing, the development of a suitable ceramic crucible melting technique will be a major achievement to mass production and widespread dissemination of titanium-based parts into the market-place as engineering components.

\section{Critical processing variables in TiAl melting}

Due to the high reactivity of titanium alloys with oxygen, carbon and nitrogen, melting has to be done in vacuum or controlled atmosphere. Although a crucial requirement to melt $\mathrm{Ti}$ alloys, vacuum melting can be detrimental to the chemical composition accuracy of some alloys. Depending on the level of vacuum in the melting chamber, loss by evaporation of elements with high vapour pressure can be very significant. This aspect is particularly important when melting Ti-Al-based alloys due to the high vapour pressure of $\mathrm{Al}$, which is 300 times higher than $\mathrm{Ti}$ in TiAl melts [30], and its low melting temperature when compared with Ti. Depending on the vacuum pressure and the melting technique $\mathrm{Al}$ loss by evaporation in TiAl melts can reach $15 \mathrm{wt} \%$ [31], which is of extremely relevance since the microstructure and mechanical properties of TiAl alloys are very sensitive to the $\mathrm{Al}$ content [32].

Some researchers [30, 31] developed and validated experimentally a theoretical model establishing a critical

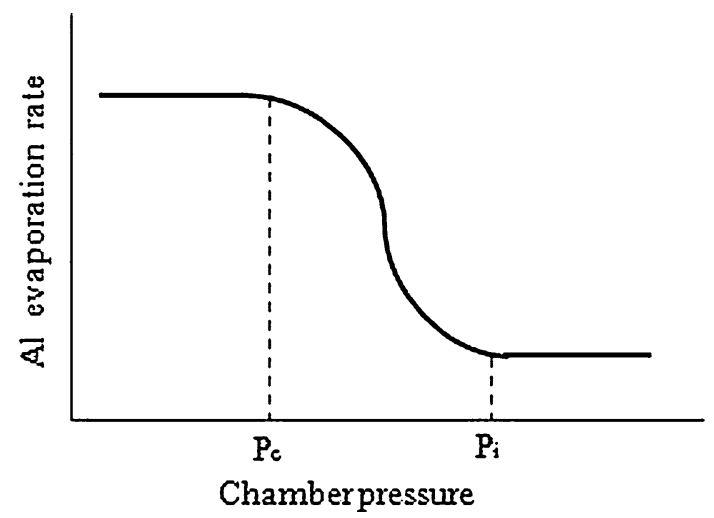

Fig. 1 Influence of chamber pressure on $\mathrm{Al}$ evaporation rate on TiAl melts, according to $[26,27]$

$\left(P_{\mathrm{c}}\right)$ and an impeding $\left(P_{\mathrm{i}}\right)$ chamber pressure that describes the $\mathrm{Al}$ evaporation loss during ISM of TiAl alloys. Below $P_{\mathrm{c}}, \mathrm{Al}$ evaporation rate is very high and above $P_{\mathrm{i}}$ it is almost irrelevant. Between the critical and impeding pressures, the $\mathrm{Al}$ evaporation rate changes very sharply (Fig. 1). According to the theoretical model, $P_{\mathrm{c}}$ and $P_{\mathrm{i}}$ of $\mathrm{Al}$ evaporation in TiAl melts with $\mathrm{Al}$ content between 25 and $50 \%$ can be calculated through Eqs. 1 and 2, as functions of melt temperature and the molar fraction of Al.

$P_{\mathrm{c}}=A-B X+C X^{2}$,

$P_{\mathrm{i}}=D-E X+F X^{2}$.

In these equations, $\mathrm{X}$ is the molar fraction of $\mathrm{Al}$ in the TiAl alloy and A to $\mathrm{F}$ are variables dependent on the melt temperature that are given by Eqs. 3-8.

$A=199.04845-0.22212 T+\left(6.222 \times 10^{-5}\right) T^{2}$,

$B=14.03203-0.01568 T+\left(4.39543 \times 10^{-6}\right) T^{2}$,

$C=0.28073-\left(3.138 \times 10^{-4}\right) T+\left(8.8 \times 10^{-8}\right) T^{2}$,

$D=36556.18112-40.03745 T+0.01097 T^{2}$,

$E=2441.3252-2.67353 T+\left(7.3235 \times 10^{-4}\right) T^{2}$,

$F=40.81973-0.04471 T+\left(1.22483 \times 10^{-5}\right) T^{2}$,

where $T$ is the melt temperature.

The best solution is to melt slightly above $P_{\mathrm{i}}$, and it is common practice to backfill the furnace melting chamber with some sort of inert gas until reaching the desired pressure level, after evacuating the chamber several times to reduce oxygen and nitrogen to the minimum possible levels.

Although this technique and the theoretical model of $\mathrm{Al}$ loss developed by Yanqing and Jingjie [30, 31] is generally accepted by ISM foundrymen, its applicability to ceramic crucible induction melting is not known, because specific studies of $\mathrm{Al}$ loss when using this technique are not 
available. In this case, besides Al loss, metal-crucible interaction has to be considered, since a significant change in the chemical composition of the alloys may change the mechanisms of metal-mould interaction. Therefore, the requirements of ceramic crucible induction melting suggest that melting pressure should be kept as low as possible to avoid metal contamination, without inducing excessive $\mathrm{Al}$ evaporation, meaning that an ideal pressure level has to be identified.

Moreover, due to the inherent poor thermal shock resistance of ceramic crucibles, heating rates are necessarily low, increasing the melting time, thus the extension of a possible metal-crucible interaction, as well as the amount of $\mathrm{Al}$ loss. Both phenomena are time, temperature and pressure dependent, therefore the correct combination of these three parameters is a key issue to obtain castings with accurate chemical composition and free from residual contamination.

In this work, different combinations of these three variables were tested and characterized its influence in the alloys chemical composition, microstructure and microhardness.

\section{Experimental procedure}

\section{Materials and experimental set-up}

A Ti-48Al alloy was selected for melting and prepared from commercially pure titanium rod and aluminium, whose compositions are presented in Table 1. Melting charges weighing $1.3 \times 10^{-1} \mathrm{~kg}$ were melted in a Linn Hightherm 700 VAC ceramic crucible induction melting furnace equipped with a $6.5 \mathrm{dm}^{3}$ melting/pouring chamber. The melting crucible was an $\varnothing 40 \mathrm{~mm} \times 80 \mathrm{~mm}$ home made zircon $\left(\mathrm{ZrO}_{2} \cdot \mathrm{SiO}_{2}\right)$-based crucible with an approximate $200-\mu \mathrm{m}$ thick inner $\mathrm{Y}_{2} \mathrm{O}_{3}$ layer (Fig. 2), which was measured on a SEM equipment. The base crucible was produced by slip casting using an emulsion of zircon in water and fired to achieve the necessary green strength for manipulation and application of the $\mathrm{Y}_{2} \mathrm{O}_{3}$ layer. This layer was centrifugally applied using an emulsion of $\mathrm{Y}_{2} \mathrm{O}_{3}$ in alcohol commercially available from ZYP Coatings, USA (the solid component was $99.9 \% \mathrm{Y}_{2} \mathrm{O}_{3}$, with grain size

Table 1 Chemical composition of commercially pure $\mathrm{Ti}$ and $\mathrm{Al}$ used to produce the $\mathrm{Ti}-48 \mathrm{Al}$ alloys

\begin{tabular}{lllllllllll}
\hline Element & \multicolumn{10}{l}{ Chemical composition $(w t \%)$} \\
\cline { 2 - 10 } & O & H & N & C & Fe & Ti & Si & Cu & Al \\
\hline Ti CP & 0.23 & 0.01 & 0.03 & 0.06 & 0.12 & $>99.5$ & - & - & - \\
$\mathrm{Al} \mathrm{CP}$ & $<0.05$ & - & - & - & 0.10 & - & 0.05 & 0.01 & $>99.8$ \\
\hline
\end{tabular}

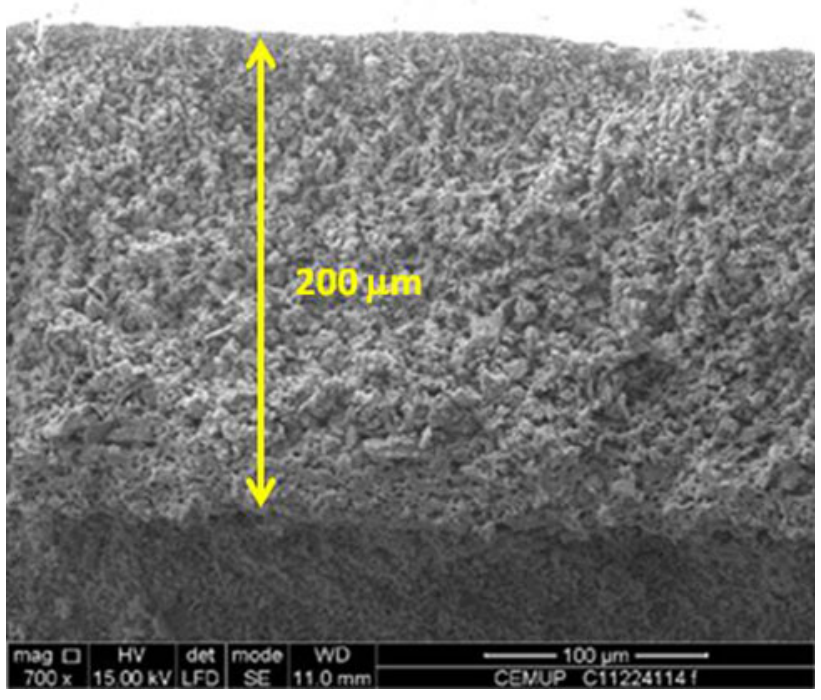

Fig. 2 Fracture surface of a crucible wall, showing the $\mathrm{Y}_{2} \mathrm{O}_{3}$ layer and the zircon substrate. It is perceptible the increasing grain size from the external side of the $\mathrm{Y}_{2} \mathrm{O}_{3}$ layer to the inside

1-5 $\mu \mathrm{m})$. This procedure led to a functionally graded coating, with particle size increasing from the inside (crucible inner wall) to the outside (zircon-yttria interface). The multi-layer crucible was then sintered at $1450{ }^{\circ} \mathrm{C}$, and the above referred graded effect led to a fully sintered coating surface with low porosity (Fig. 3a), and an internal partially sintered region with high porosity (Fig. 3b). This coating morphology is extremely important to avoid or decrease the erosion of the crucible wall while maintaining high thermal shock resistance.

Every crucible used on this work has been characterized in order to assure that only crucibles with similar morphologies and coating thickness were used for melting. For that purpose, a small sample was taken from the top of the crucible wall, making two parallel longitudinal cuts with a diamond saw and breaking the remaining connection to the crucible wall. Microstructures presented on Figs. 2 and 3 were taken from the fracture surface of those samples and were obtained on a high-resolution FEI Quanta 400 FEG E Scanning Electron Microscope. The average crucibles porosity was $35 \pm 3 \%$, evaluated according to the ISO Standard 5017:1998(E). The average coating surface porosity was $14 \pm 2 \%$, evaluated by digital imaging techniques, using Image Pro plus software.

For melting, the multilayer crucible was positioned inside a home made $\mathrm{ZrO}_{2} \cdot \mathrm{SiO}_{2}$ pouring crucible with lip (Fig. 4).

The melting stock was positioned inside the crucible in a way that the titanium was located above the aluminium fragments in order to avoid direct contact between the $\mathrm{Ti}$ fragments and the crucible wall during heating, thus 

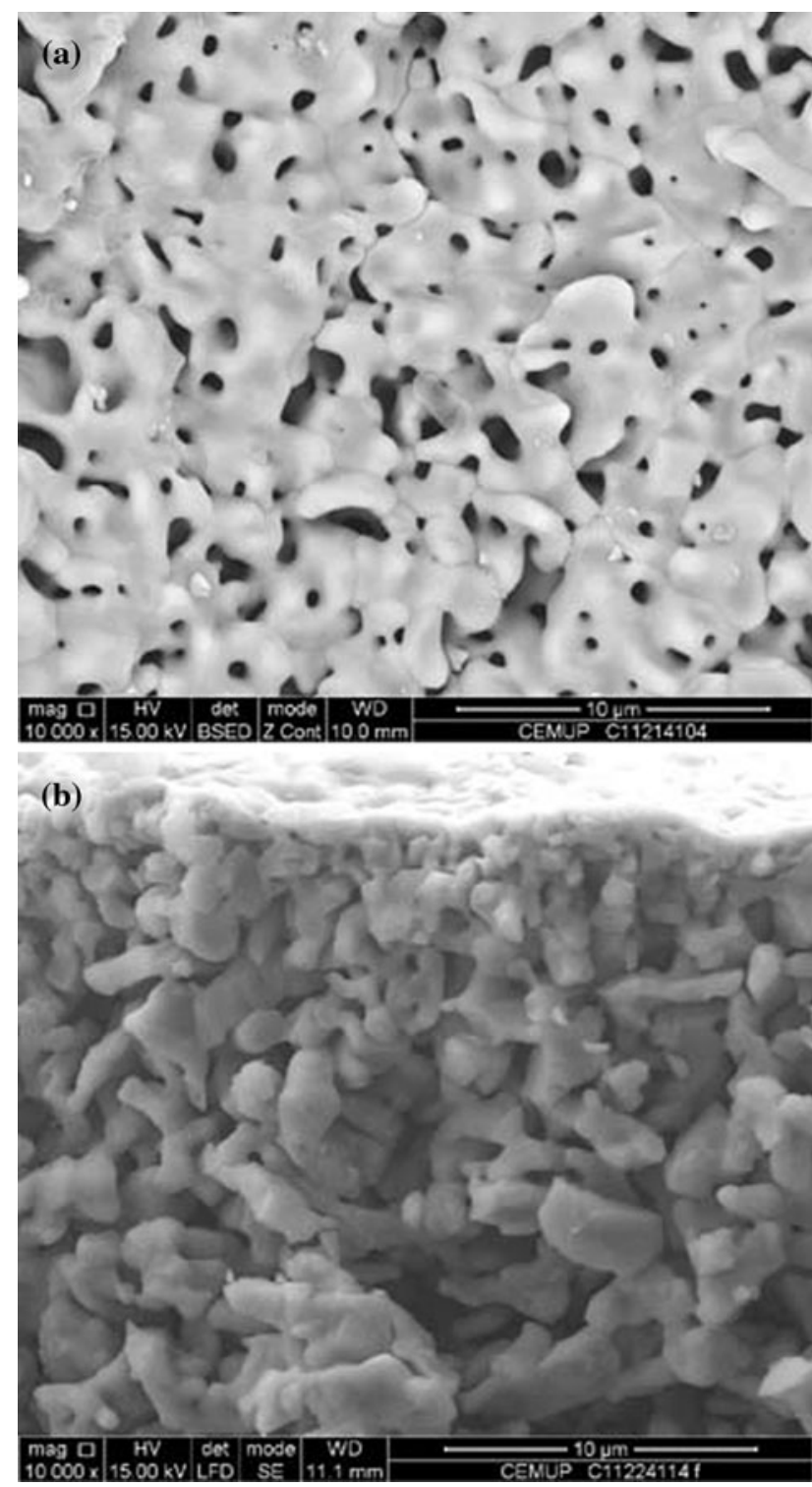

Fig. 3 a Fully sintered surface of the $\mathrm{Y}_{2} \mathrm{O}_{3}$ coating, with $14 \%$ porosity. b Detail of the yttria coating, revealing a fully sintered external surface and a partially sintered interior region with high porosity

minimizing Ti-crucible contact time. A graphite mould with $\varnothing 20 \times 120 \mathrm{~mm}$ cylindrical cavity was used to pour the molten alloys, in order to isolate the effect of oxygen pickup exclusively from the crucible, during the melting operation.

\section{Melting procedure and parameters}

Melting was performed inside a sealed chamber, in vacuum or under a controlled atmosphere of commercially pure dry argon (medical grade- $\mathrm{O}_{2}<10 \mathrm{ppm} ; \mathrm{N}_{2}<5 \mathrm{ppm}$; $\mathrm{H}_{2} \mathrm{O}<1 \mathrm{ppm}$ ). Before the heating cycle, the chamber was evacuated down to $10^{-3}$ mbar and back-filled with argon

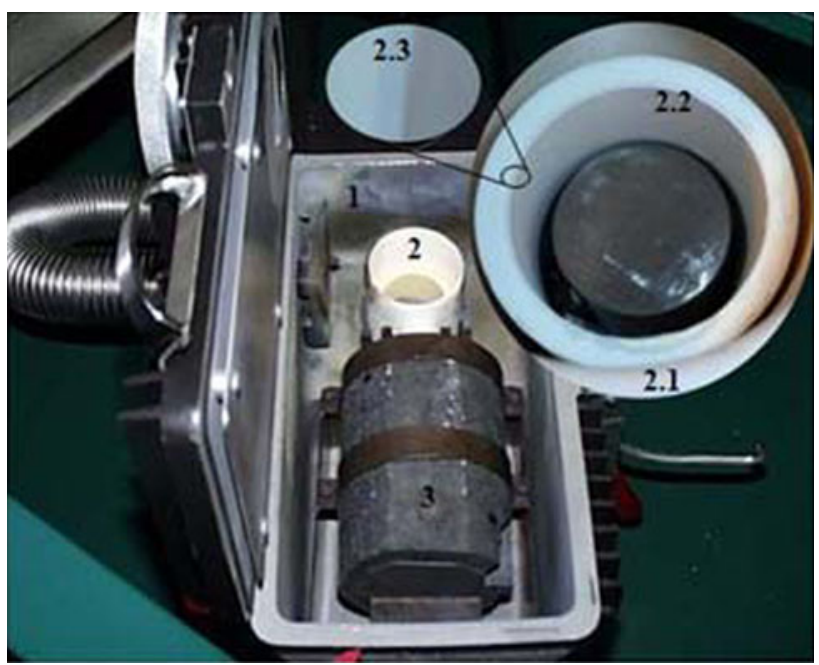

Fig. 4 Experimental set-up and positioning of the melting stock inside the crucible. 1 Furnace chamber, 2 Crucible set, 3 Graphite die, 2.1 Pouring crucible, 2.2 Melting crucible, and 2.3 $\mathrm{Y}_{2} \mathrm{O}_{3}$ layer

five times, in order to reduce the oxygen content to a minimum level. Melting pressures were then selected taking into account the critical and impeding pressures $P_{\mathrm{c}}$ and $P_{\mathrm{i}}$ suggested by the theoretical model developed for ISM. By applying Eqs. 1 and 2 for melting temperatures of 1875 and $1925 \mathrm{~K}$, theoretical $P_{\mathrm{c}}$ and $P_{\mathrm{i}}$ for a Ti-48Al alloy are $1.23 \times 10^{-2}$ and $1.5 \times 10^{-1} \mathrm{mbar}$, for $1875 \mathrm{~K}$, and $1.86 \times 10^{-2}$ and $4.6 \times 10^{-1} \mathrm{mbar}$, for $1925 \mathrm{~K}$, respectively. According to the calculated values, melting pressures slightly above $P_{\mathrm{i}}$ and slightly below $P_{\mathrm{c}}$, as well as some intermediate values were selected to perform this study.

The heating operation was always performed at constant power and the alloy that was forming remained on a mushy state due to the dissolution of titanium in aluminium, which gradually increased the melting temperature of the alloy. During melting, the pressure inside the chamber was continuously monitored and a slight increase was noticed as the melt temperature rose. Although it was not very significant, due to the large size of the melting chamber compared to the size of the melting stock, and the continuous air cooling of the chamber wall, the pressure was periodically adjusted by opening the vacuum pump valve for short periods of time, using an OFF/Gas/Vacuum switch and a gas flux regulator included in the furnace control panel. When the temperature reached $1785 \pm 10 \mathrm{~K}$, around $15 \mathrm{~min}$ after starting the heating cycle, the first liquid became visible. Power was then increased to increase the heating rate, in order to decrease the contact time of the liquid alloy with the ceramic crucible, and a type $\mathrm{B}(\mathrm{Pt} / \mathrm{Pt}-\mathrm{Rd})$ thermocouple protected by a $\mathrm{Mo}-\mathrm{Al}_{2} \mathrm{O}_{3}-\mathrm{ZrO}_{2}$ refractory sheath (metalceramic composite-Metamic Sheath 829 supplied by DFC 
Thermal Ceramics Limited) was periodically immersed until reaching the desired superheating (due to the very fast response of the thermocouple, thus the short melt-composite contact time, and the high thermodynamical stability of the sheath material, no dissolution of sheath seemed to have occurred, since no traces of Mo and $\mathrm{Zr}$ have been found in the cast alloy, and no visual damage was detected on the sheath wall). Melts were then maintained at the selected temperatures (1875 and $1925 \mathrm{~K}$ ) for 60 and $90 \mathrm{~s}$ before being centrifugally poured at $400 \mathrm{rpm}$ into the graphite mould. For the sake of comparison, samples were also poured immediately after reaching the selected casting temperatures. During cooling, temperature measurement was performed using a wireless receiver/transmitter-receiver data acquisition system compatible with the centrifugal casting process, developed at the University of Minho.

Table 2 presents the melting variables combinations used in this work to melt the $\mathrm{Ti}-48 \mathrm{Al}$ alloys.

\section{Samples characterization}

Samples for characterization were collected from the middle of the cast cylinders by sectioning them at $50 \%$ of their height. X-ray diffraction using a Rigaku, model Geigerflex D/max-C Series equipment using $\mathrm{Cu} \mathrm{K} \mathrm{K}_{\alpha}$ radiation was used for phase identification. Chemical composition was evaluated by quantitative EDS analysis with standards of pure Ti, Al and Y using a high-resolution FEI Quanta 400 FEG E Scanning Electron Microscope coupled to an EDAX Genesis X4M X-Ray Energy Dispersive Electron Spectrometer. The error associated to $\mathrm{Ti}$ and $\mathrm{Al}$ measurements was 0.2 at. $\%$ and the error of $\mathrm{Y}$ measurement was 0.05 at. $\%$. $10 \mathrm{keV}$ potential and $100 \mathrm{~s}$ acquisition time were used for

Table 2 Melt temperature, pressure, and superheating time combinations used in this work

\begin{tabular}{llll}
\hline Melt \# & Temperature $(\mathrm{K})$ & Time $(\mathrm{s})$ & Pressure (mbar) \\
\hline $1-3$ & 1875 & $0,60,90$ & 0.005 \\
$4-6$ & 1925 & $0,60,90$ & 0.005 \\
$7-9$ & 1875 & $0,60,90$ & 0.01 \\
$10-12$ & 1925 & $0,60,90$ & 0.01 \\
$13-15$ & 1875 & $0,60,90$ & 0.05 \\
$16-18$ & 1925 & $0,60,90$ & 0.05 \\
$19-21$ & 1875 & $0,60,90$ & 0.1 \\
$22-24$ & 1925 & $0,60,90$ & 0.1 \\
$25-27$ & 1875 & $0,60,90$ & 0.15 \\
$28-30$ & 1925 & $0,60,90$ & 0.15 \\
$31-33$ & 1875 & $0,60,90$ & 0.5 \\
$34-36$ & 1925 & $0,60,90$ & 0.5 \\
$37-39$ & 1875 & $0,60,90$ & 1 \\
$40-42$ & 1925 & $0,60,90$ & 1 \\
\hline
\end{tabular}

every evaluation. Overall oxygen content was measured by the IGF technique (Inert Gas Fusion) on a Lecco TC-136 analyser, with an associated error of $20 \mathrm{ppm}$. Microhardness was evaluated on a Shimadzu hardness tester using a 50-g load for $15 \mathrm{~s}$. Image Pro Plus was used for image treatment and to quantify the volume fraction of constituents.

\section{Results and discussion}

\section{Microstructure}

In every cast sample, the microstructure was fully lamellar with two phases- $-\alpha_{2}+\gamma$-at distances from the surface of less than $4 \mathrm{~mm}$ (Figs. 5, 6) due to the high cooling rate achieved in the graphite mould (Fig. 7). This is the typical microstructure of as-cast $\gamma$-TiAl alloys with Al content around 48 at.\% when cooling rates between 0.2 and $1 \mathrm{Ks}^{-1}$ are used [33].

In those samples cast under pressures higher than 0.01 mbar at $1925 \mathrm{~K}$ with 60 and $90 \mathrm{~s}$ superheating times, small grains of $\gamma$ phase (TiAl) appeared at longer distances from the surface, at the boundaries of the lamellar grains $\left(\mathrm{Ti}_{3} \mathrm{Al}+\mathrm{TiAl}\right)($ Fig. 8) in a volume fraction between 4 and $6 \%$, following the decrease in the cooling rate. For chamber pressures below that value, microstructure was fully lamellar all over the samples. The absence of the secondary $\gamma$ phase in the bulk of samples cast at pressures below 0.01 mbar at $1925 \mathrm{~K}$ might be a consequence of the final composition of those alloys, which average $\mathrm{Al}$ content was 43.75 and 42.30 at.\% for 60 and $90 \mathrm{~s}$ superheating time, respectively. Due to the low $\mathrm{Al}$ content, those alloys did not suffer peritectic reaction at $1765 \mathrm{~K}$, which changed their solidification sequence [34].

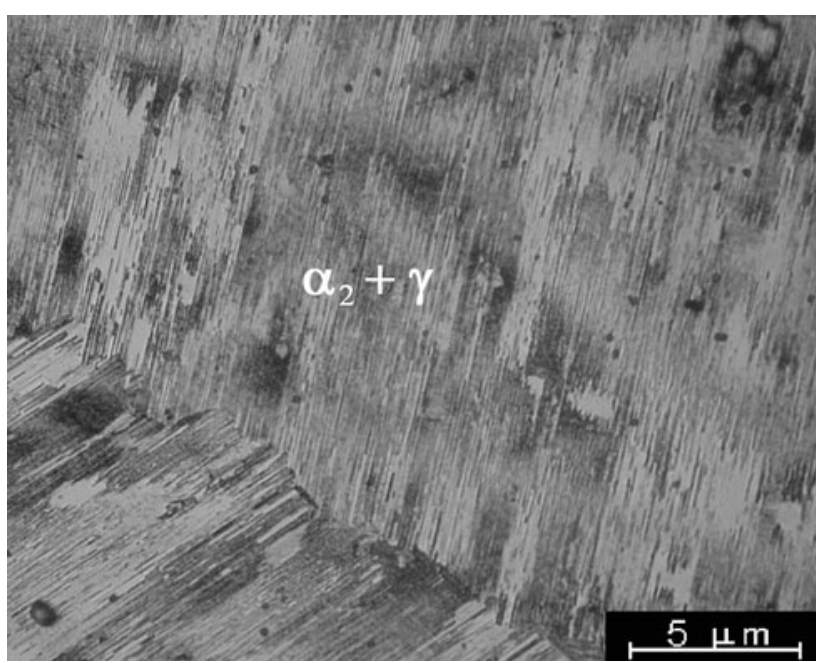

Fig. 5 Microstructure of a $\mathrm{Ti}-48 \mathrm{Al}$ sample cast in graphite mould, at $500 \mu \mathrm{m}$ from surface 


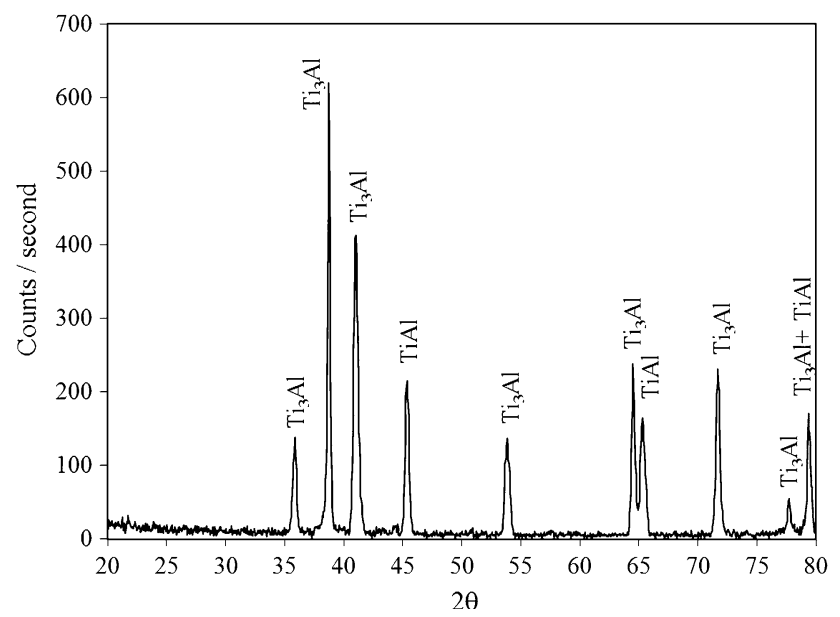

Fig. $6 \mathrm{X}$-ray diffraction spectrum of a cast $\mathrm{Ti}-48 \mathrm{Al}$ sample, revealing the co-existence of $\mathrm{Ti}_{3} \mathrm{Al}$ and $\mathrm{TiAl}$

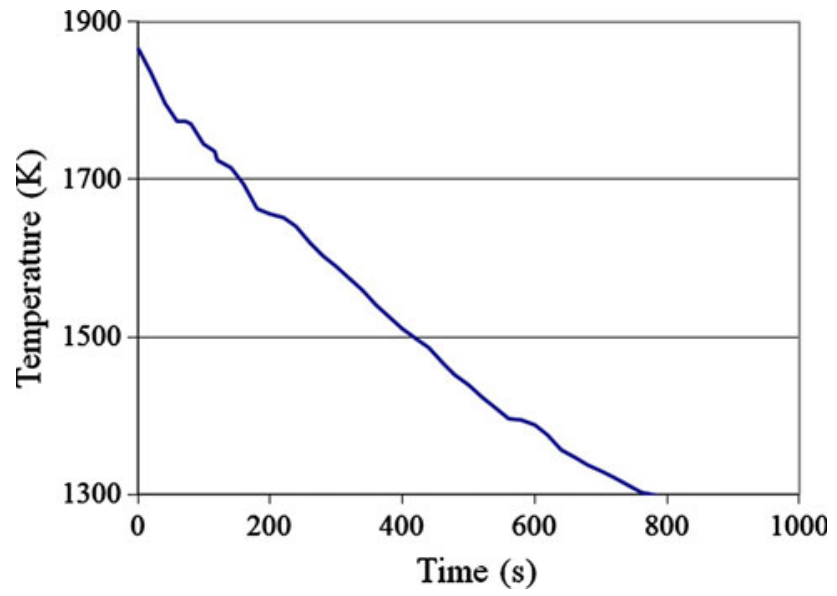

Fig. 7 Cooling curve of a $\varnothing 20 \mathrm{~mm}$ cylindrical Ti-48Al sample in graphite mould. Average cooling rate from 1865 to $1300 \mathrm{~K}$ was $0.9 \mathrm{~K} / \mathrm{s}$

The microstructure at the surface (metal-mould interface) of cast samples was not affected by the pouring temperature or the chamber pressure. In every cast sample, only the lamellar structure $\alpha_{2}+\gamma$ was detected (Fig. 9). Although it could be expected that the high reactivity of titanium with carbon would have led to the formation of $\mathrm{TiC}$, especially at the metal-mould interface, it seems that the reaction did not occur, which may have been a consequence of the high cooling rate that decreased the reaction kinetics.

In those samples cast at $1925 \mathrm{~K}$ after $90 \mathrm{~s}$ holding time, with chamber pressures of 0.5 and 1 mbar, besides the referred lamellar structure small white particles with less than $0.5 \mu \mathrm{m}$ were found dispersed in the metal matrix (Fig. 10), on a volume fraction around $0.2 \%$. An EDS analysis revealed that those particles were yttrium oxide (Fig. 11), suggesting that a stronger interaction of the

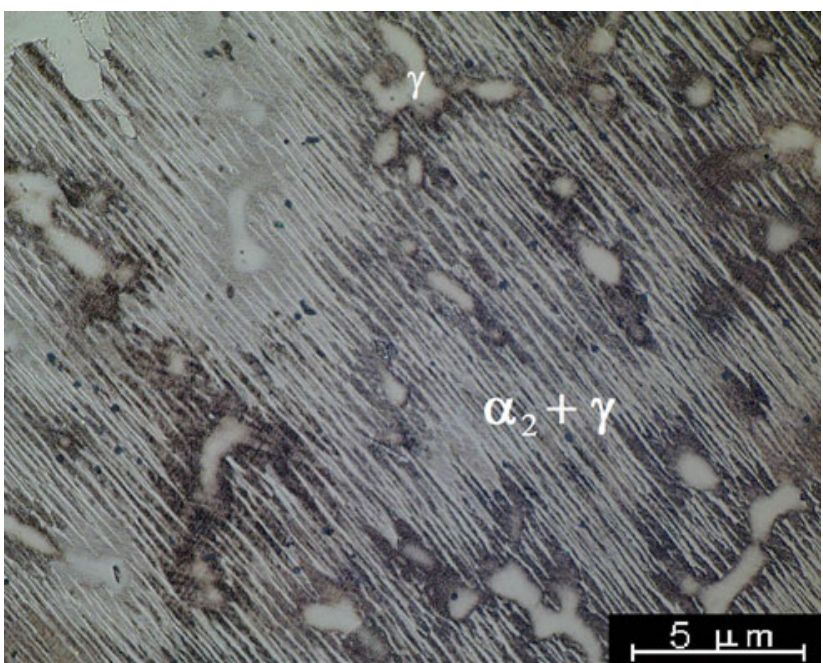

Fig. 8 Microstructure of a Ti-48Al sample cast in graphite mould, at $5 \mathrm{~mm}$ from surface, revealing the co-existence of a lamellar $\alpha_{2}+\gamma$ constituent and a $\gamma$ phase

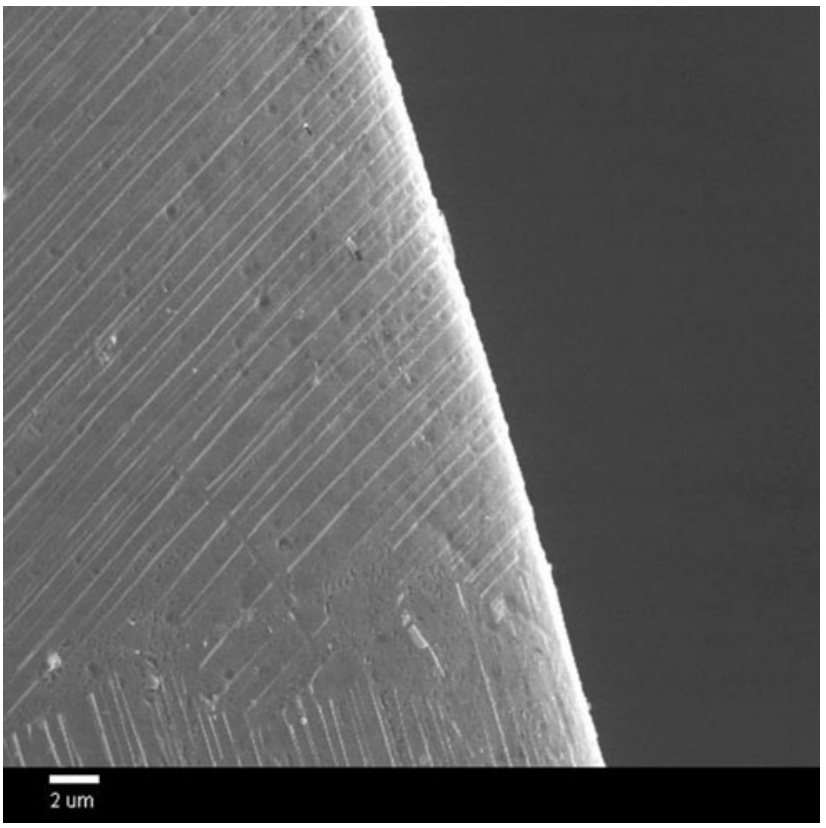

Fig. 9 Fully lamellar structure at the surface of a Ti-48Al sample cast in graphite mould, after $60 \mathrm{~s}$ holding time at $1925 \mathrm{~K}$

molten alloy with the crucible yttria layer occurred for those superheating parameters. For pressure values below 0.5 mbar, no yttria particles were found. The most probable cause for $\mathrm{Y}_{2} \mathrm{O}_{3}$ inclusions is an erosion phenomenon and distribution of detached yttria grains in the molten alloy, which agrees with previous findings of both the authors [26] and other researchers [35, 36]. The most probable cause of erosion of the yttria layer might have been a combination of several factors, namely the melt fluidity at $1925 \mathrm{~K}$ combined with the relative movement between the crucible wall and the melt due to the electromagnetic 


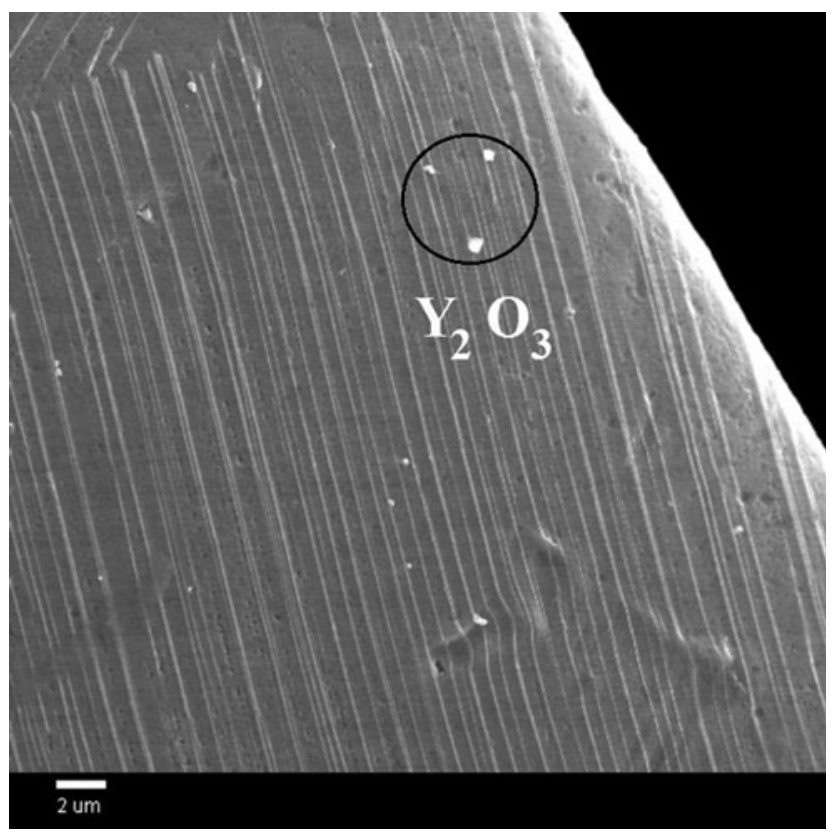

Fig. 10 Fully lamellar structure with $\mathrm{Y}_{2} \mathrm{O}_{3}$ inclusions at the surface of a Ti-48Al sample cast in graphite mould, after $90 \mathrm{~s}$ holding time at $1925 \mathrm{~K}$

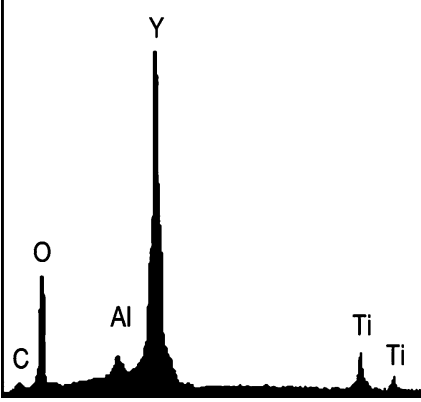

Fig. 11 EDS spectrum of an $\mathrm{Y}_{2} \mathrm{O}_{3}$ particle present at the microstructure presented on Fig. 8. $\mathrm{Ti}$ and $\mathrm{Al}$ peaks appear due to the interaction of the surrounding metallic matrix

stirring (as referred by Renjie et al. [36]) and the long superheating time $(90 \mathrm{~s})$. Together, these three factors made it easy the molten alloy to promote grain separation and its distribution through the molten alloy. Moreover, in those experiments carried out at $1925 \mathrm{~K} / 60 \mathrm{~s}$ (Fig. 9) less than $0.05 \%$ inclusions of "white particles" (later identified by EDS as yttrium oxide) were found, and at $1875 \mathrm{~K}$ no yttria particles were found, both for 60 and $90 \mathrm{~s}$ superheating time. This reveals that the presence of $\mathrm{Y}_{2} \mathrm{O}_{3}$ particles in the matrix is directly related to the specific superheating parameters, especially temperature.

The absence of inclusions in those samples cast at pressures below 0.5 mbar supports the principle that fluidity plays a crucial role on the erosion phenomenon. In fact, the

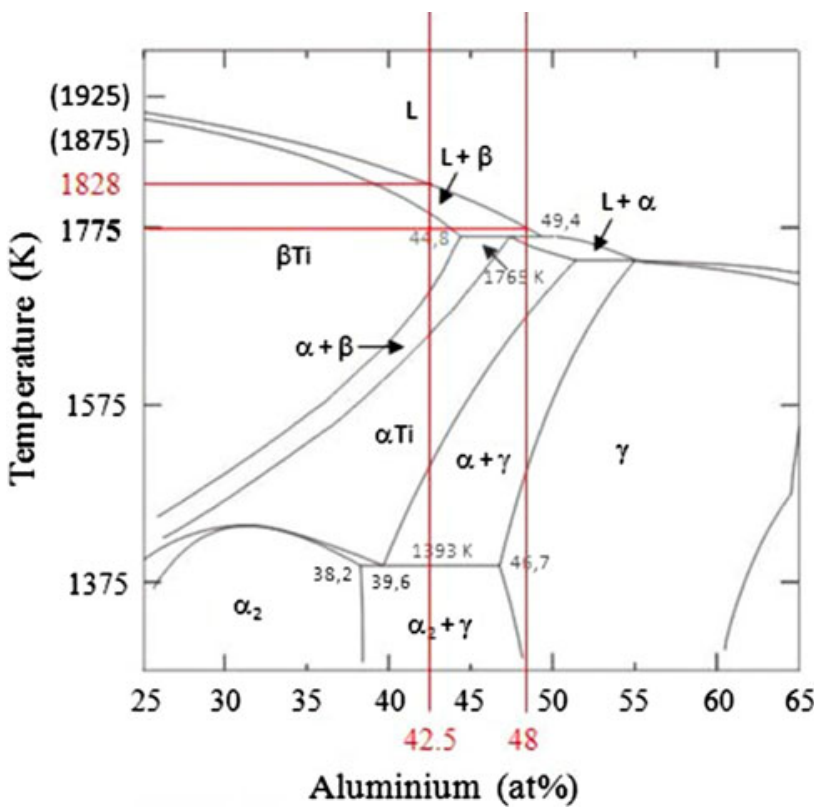

Fig. 12 Central section of the $\mathrm{Ti}-\mathrm{Al}$ phase equilibria diagram proposed by Okamoto [30] and positioning of the $\mathrm{Ti}-48 \mathrm{Al}$ alloy and the one with lower $\mathrm{Al}$ content $(42.5$ at.\%) obtained on this work

chamber pressure has a great influence on the final alloy composition, since low pressures favours $\mathrm{Al}$ evaporation and can significantly change the alloy composition, as presented in the next sections of this article. The $\mathrm{Al}$ content of those samples cast at $1925 \mathrm{~K} / 90 \mathrm{~s}$ using 0.5 and $1 \mathrm{mbar}$ was 47.26 and 47.0 at.\%, respectively, and those values were the highest of every sample produced on the aim of this research. According to the $\mathrm{Ti}-\mathrm{Al}$ phase equilibrium diagram (Fig. 12), the liquidus temperature of a Ti-Al alloy with 47 at.\% $\mathrm{Al}$ content is approximately $1787 \mathrm{~K}$ and increases for lower $\mathrm{Al}$ contents. As a consequence, those alloys presented the higher superheating temperatures among all the compositions obtained on this research, thus the highest fluidity, which could have led to the most extent erosion phenomenon of the crucible wall.

\section{Chemical composition}

\section{Al content}

In every cast sample smoke started to escape from the melting crucible, condensing as a light grey powder on the furnace glass window, at a temperature slightly below that, corresponding to the first visible liquid metal (1785 \pm $10 \mathrm{~K}$ ). The amount of powder condensing at the furnace window increased with increasing superheating time and temperature, and it was particularly important when the pressure inside the chamber was below 0.01 mbar. An EDS analysis revealed that condensed powder was basically pure aluminium that evaporated during melting, confirming the 
findings of other authors for induction skull melting $[16,30]$, electron beam melting [37, 38], and vacuum arc melting [39].

On Table 3, the final Al content of the theoretical Ti-48Al alloys is presented for different superheating times/temperatures combinations and chamber pressures. It is clear that $\mathrm{Al}$ loss increases significantly with the superheating parameters and decreasing chamber pressures, between two threshold pressure levels.

For $1875 \mathrm{~K}$, Al loss was almost negligible for chamber pressures above $0.15 \mathrm{mbar}$, both for 60 and $90 \mathrm{~s}$ superheating time $(0.24$ at. $\%$ for $1 \mathrm{mbar} / 60 \mathrm{~s}$ to 0.36 at. $\%$ for $0.15 \mathrm{mbar} /$ $90 \mathrm{~s}$ ) increasing gradually as the chamber pressure dropped and superheating time increased, until reaching a maximum value of 3.45 at.\% for $90 \mathrm{~s}$ holding time at both 0.01 and 0.005 mbar. For $1925 \mathrm{~K}, \mathrm{Al}$ loss followed the same trend, although the amount of lost $\mathrm{Al}$ mass was higher for this temperature. In this case, Al loss values were quite similar for pressures above $0.5 \mathrm{mbar}$, independently from the holding time ( 0.55 at. $\%$ for $0.5 \mathrm{mbar} / 60 \mathrm{~s}$ to 0.70 at. $\%$ for $1 \mathrm{mbar} /$ $90 \mathrm{~s}$ ), increasing gradually as the chamber pressure decreased and superheating time increased, until reaching maximum values of 5.6 and 5.8 at.\% for $90 \mathrm{~s}$ holding time at $0.01 \mathrm{mbar}$ and 0.005 mbar, respectively. From Table 3, it is also clear that $\mathrm{Al}$ evaporation besides being proportional to the melt temperature was also proportional to the interval of time that the alloy was in the liquid state before pouring. The $\mathrm{Al}$ loss was identical to that referred by Yanqing et al. [30] in the case where the processing conditions were similar, thus comparable (1.2 at.\% in both cases for $1925 \mathrm{~K} / 0.01 \mathrm{mbar}$, without holding time—-see Table 3). Hadi et al. [39] referred values of $\mathrm{Al}$ loss around 2 at.\% after three remelts on vacuum arc melting of a Ti-47 Al alloy made of elemental $\mathrm{Al}$ and $\mathrm{Ti}$ at 400 mbar, which represented around 0.6-0.7 at.\% Al loss/ melt. Although the authors do not refer to melting temperature, in cold crucible arc melting furnaces superheating temperature and time are always very low, due to the extremely high cooling rates achieved in the cold crucible. Hence, if we consider that superheating was something around $100 \mathrm{~K}$ and that $\mathrm{Al}$ loss was not very different from that hypothetically obtained for 0.5 or 1 mbar (the $\mathrm{Al}$ evaporation impeding pressure should be inside the interval of $0.15-0.5$ mbar for that temperature range), the referred values were of the same magnitude of those obtained on this work for pressures above 0.5 mbar (0.15-0.7 at.\%-see Table 3).

Values presented in Table 3 were converted to Al loss/ time unit, and the results are presented in Fig. 13 as the variation of $\mathrm{Al}$ loss rate with the experimental processing variables. Each point of both curves represents the average value between the results obtained for 60 and 90 s superheating time experiments, which curves of $\mathrm{Al}$ loss rates matched almost exactly.

From Fig. 13, it is evident the existence of two threshold level pressures which correspond to the critical $\left(P_{\mathrm{c}}\right)$ and impeding $\left(P_{\mathrm{i}}\right) \mathrm{Al}$ evaporation pressures referred before in this article and validates the theoretical model developed by Yanqing [30] and Jingjie [31] for ISM. For $1875 \mathrm{~K}$ melt temperature, Al loss rate was almost constant for pressures above $0.15 \mathrm{mbar}\left(P_{\mathrm{i}}\right)$ and below $0.01 \mathrm{mbar}\left(P_{\mathrm{c}}\right)$, increasing very fast between those values as the melting chamber pressure decreases. For $1925 \mathrm{~K}$, the Al loss rate curve followed the same trend, but while the critical pressure

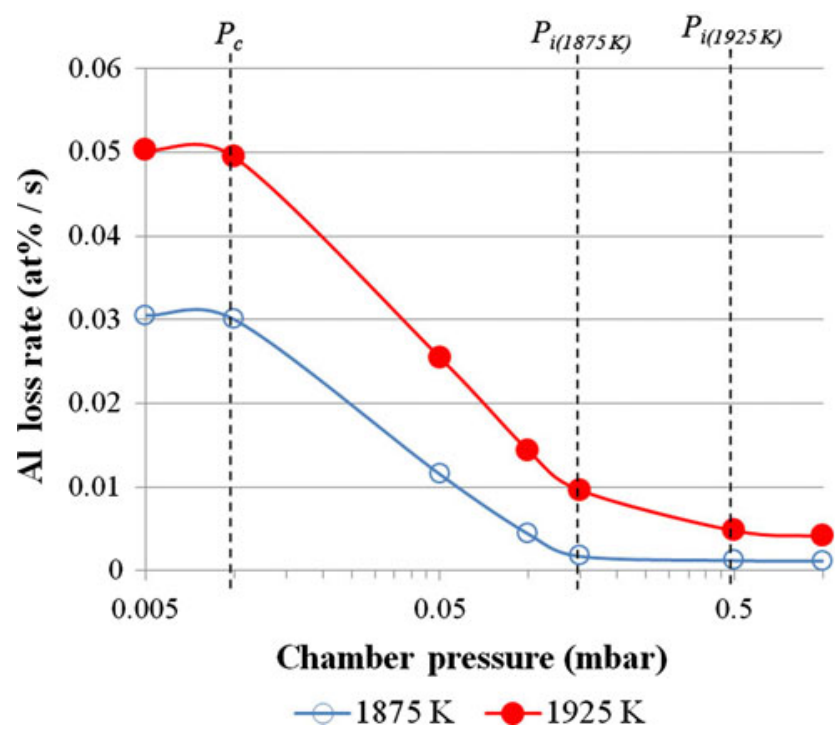

Fig. 13 Aluminium loss rate (in at.\%/s) in ceramic crucible induction melted $\mathrm{Ti}-48 \mathrm{Al}$ alloys as a function of melting chamber pressure and melt temperature
Table 3 Final Al content of induction melted $\mathrm{Ti}-48 \mathrm{Al}$ alloys for different casting temperatures and superheating times, at different melting chamber pressures

\begin{tabular}{lcccccccc}
\hline $\begin{array}{l}\text { Temperature } \\
(\mathrm{K})\end{array}$ & Time $(\mathrm{s})$ & \multicolumn{7}{l}{ Melting chamber pressure (mbar) } \\
\cline { 2 - 8 } & & 0.005 & 0.01 & 0.05 & 0.1 & 0.15 & 0.5 & 1 \\
\hline 1875 & 0 & 47.25 & 47.25 & 47.60 & 47.70 & 47.80 & 47.80 & 47.85 \\
1875 & 60 & 45.40 & 45.45 & 46.90 & 47.45 & 47.70 & 47.75 & 47.76 \\
1875 & 90 & 44.55 & 44.55 & 46.60 & 47.30 & 47.64 & 47.67 & 47.70 \\
1925 & 0 & 46.70 & 46.80 & 47.25 & 47.53 & 47.65 & 47.75 & 47.68 \\
1925 & 60 & 43.70 & 43.80 & 45.73 & 46.70 & 47.10 & 47.45 & 47.44 \\
1925 & 90 & 42.20 & 42.40 & 44.95 & 46.22 & 46.78 & 47.35 & 47.30 \\
\hline
\end{tabular}


was close to the one observed for $1875 \mathrm{~K}$, the impeding pressure was higher $(0.5 \mathrm{mbar})$. These values were very similar to those calculated using the theoretical (and experimentally validated) model developed for ISM [30, 31] for the melting temperatures and alloy composition used on this work, and presented on Table 2, suggesting that the model developed for ISM can be successfully used to anticipate the dynamics of $\mathrm{Al}$ loss in ceramic crucible induction melting of Ti-Al alloys with composition close Ti-48Al.

Knowledge of the $\mathrm{Al}$ evaporation rate and the critical and impeding pressures for a specific $\mathrm{Ti}-\mathrm{Al}$ alloy composition as well as melting techniques and conditions are crucial factors to produce high quality alloys with accurate chemical composition. From the presented results and references of other researchers, we can deduce that adjusting and controlling temperature, holding time and melting pressure it is possible to achieve such goals. Nevertheless, due to other reasons like the presence of other alloying elements with high melting temperature, or the casting thickness/geometry, for example, it may be necessary to use processing parameters that may lead to significant Al loss. In such cases, a possible solution to solve the problem is to increase the $\mathrm{Al}$ content in the melting stock in order to compensate the expected loss. To make such procedure easier, the mass of evaporated aluminium was calculated from the final atomic \% composition of the alloys, based on the principle that most of the mass loss is attributable to $\mathrm{Al}$ evaporation [16, 30]. Moreover, the $\mathrm{Al}$ evaporation rate depends on the free surface of evaporation (which corresponds to the upper surface of the molten alloy), thus on the inside crucible radius [30, 31]. In Fig. 14, the variation of $\mathrm{Al}$ loss rate per unit of surface as a function of the chamber pressure, for the evaluated melt temperatures and crucible size used in this work is presented.

For $1875 \mathrm{~K}, \mathrm{Al}$ loss rate was from the order of $1.7 \times$ $10^{-4} \mathrm{~g} / \mathrm{cm}^{2} / \mathrm{s}$ for melting chamber pressures above 0.15 mbar and increases rapidly as the chamber pressure decreases until reaching a quasi constant value of $3 \times 10^{-3}$ $\mathrm{g} / \mathrm{cm}^{2} / \mathrm{s}$ for pressures below $0.01 \mathrm{mbar}$. For $1925 \mathrm{~K}$, the variation curve follows the same trend, but absolute values were higher especially for the lower chamber pressures. Al loss rates were around $3.5 \times 10^{-4} \mathrm{~g} / \mathrm{cm}^{2} / \mathrm{s}$ for pressures above 0.5 mbar and increased with decreasing pressure until reaching a quasi constant value of $5.4 \times 10^{-3} \mathrm{~g} / \mathrm{cm}^{2} / \mathrm{s}$ for pressures below $0.01 \mathrm{mbar}$. This behaviour agrees with references of Yanqing et al. [30] but the $\mathrm{Al}$ loss rate values obtained on this work for both temperatures were 5 and 10 times higher than those referred by that researcher, for pressures above 0.15 mbar and below 0.01 mbar, respectively. This difference can be a consequence of the crucible and melting charge size, which was much smaller in this work (300 g against $3-5 \mathrm{~kg}$ in [30]). According to

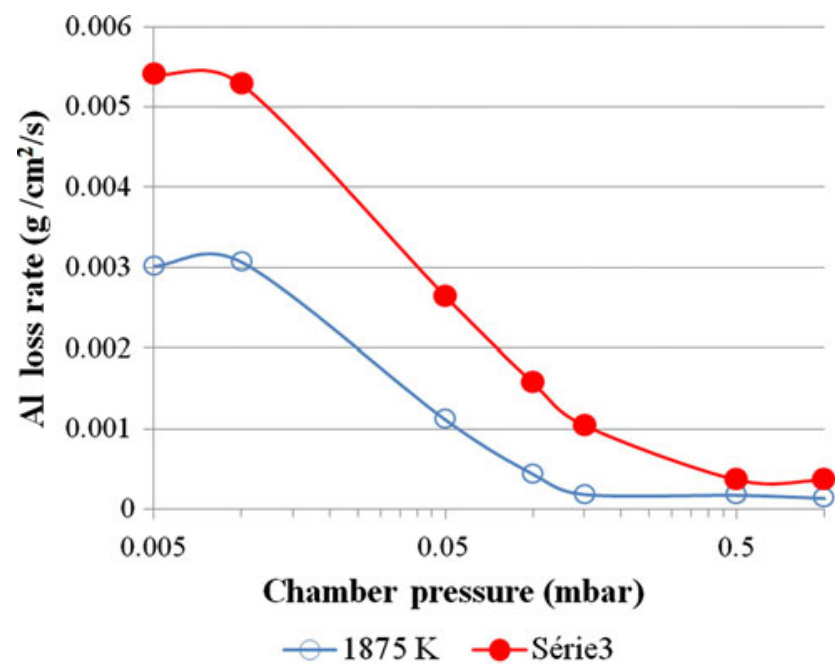

Fig. 14 Aluminium loss rate (in $\mathrm{g} / \mathrm{cm}^{2} / \mathrm{s}$ ) in ceramic crucible induction melted $\mathrm{Ti}-48 \mathrm{Al}$ alloys as a function of melting chamber pressure and melt temperature

experiments of other researchers [30,38], the charge weight/ volume has a significant influence on the evaporation loss of $\mathrm{Al}$, with bigger charges suffering less relative $\mathrm{Al}$ loss, thus smaller differences to the nominal $\mathrm{Al}$ content. Moreover, the size of the melting chamber directly influences the partial pressure of $\mathrm{Al}$ that, in turn, could also influence the $\mathrm{Al}$ loss rate. However, no experimental studies on this particular aspect were found in the consulted literature.

The calculation of the lost $\mathrm{Al}$ mass from the variation in the at.\% composition of the alloy was performed according to the following procedure:

$W_{\text {(charge) }}$ Mass of the melting charge

$M_{\text {(Ti) }} \quad$ Molar mass of titanium

$M_{\text {(Al) }} \quad$ Molar mass of Aluminium

$W_{\text {(Ti) }} \quad$ Mass of Ti in the melting charge

$W_{(\mathrm{Al})} \quad$ Mass of $\mathrm{Al}$ in the melting charge

$x \quad$ Mole fraction of $\mathrm{Ti}$ in the $\mathrm{Ti}-\mathrm{Al}$ alloy

$y \quad$ Mole fraction of $\mathrm{Al}$ in the $\mathrm{Ti}-\mathrm{Al}$ alloy

$M_{\text {(Ti-yAl) }} \quad$ Molar mass of Ti-yAl alloy

$M_{(\mathrm{Ti}-y \mathrm{Al})}=x \times M_{(\mathrm{Ti})}+y \times M_{(\mathrm{Al})}$.

The mass of each component in the melting charge can be calculated from the following equations:

$W_{(\mathrm{Ti})}=\left[x \times M_{(\mathrm{Ti})} / M_{(\mathrm{Ti}-y \mathrm{Al})}\right] \times W_{(\text {charge })}$,

$W_{(\mathrm{Al})}=\left[y \times M_{(\mathrm{Al})} / M_{(\mathrm{Ti}-y \mathrm{Al})}\right] \times W_{(\text {charge })}$.

By applying Eqs. 10 and 11 to the initial and final alloy atomic compositions, we get the theoretical initial and final values of both $W_{(\mathrm{Ti})}$ and $W_{(\mathrm{Al})}$ for the initial mass of the melting charge $W_{\text {(charge) }}$. 
Assuming that all mass loss is attributed to Al loss, then $W_{\text {(Ti) }}$ is constant along the melting operation. Thus, the real mass of $\mathrm{Al}$ (real $W_{(\mathrm{Al})}$ ) in the final alloy can be calculated from expression (12).

Real $W_{(\mathrm{Al})}=\left[\right.$ Initial $W_{(\mathrm{Ti})} /$ Final $\left.W_{(\mathrm{Ti})}\right] \times$ Final $W_{(\mathrm{Al})}$.

The mass loss of $\mathrm{Al}$ (Al loss) that corresponds to a decrease of the $\mathrm{Al}$ atomic content in the alloy can be calculated from expression (13)

$\mathrm{Al}$ loss $=$ Initial $W_{(\mathrm{Al})}-$ Real $W_{(\mathrm{Al})}$.

\section{Oxygen and yttrium enrichment}

Every cast sample was found to be contaminated with oxygen, whose concentration was higher than the one that could be attributed to the oxygen present on the components of the melting stocks. On the other hand, no significant oxygen content was expected to exist inside the melting chamber, due to the purging procedure described in the "Melting procedure and parameters" section, which is a usual technique to reduce the concentration of atmospheric elements to very low levels, in order to avoid chemical contamination of the cast alloys. Nevertheless, a residual presence of oxygen inside the chamber cannot be totally excluded since only primary vacuum levels $\left(10^{-3}\right.$ mbar $)$ were achieved on the purging operation. However, since the oxygen content inside the chamber after purging was not known, and its concentration was not expected to be significant, a possible contribution of that oxygen source to oxide formation and alloy contamination was not considered.

Thus, taking into account the oxygen content of CPTi and CPAl used on the melting stock (see Table 1), the expected maximum oxygen content should be $0.16 \mathrm{wt} \%$. Nevertheless, the oxygen concentration of every alloy was higher than that value revealing that an "oxygen enrichment" of the cast alloys had occurred. Since the entire processing (melting/ pouring/cooling) was performed under a dry argon atmosphere, which reduced the possibility of oxygen pickup, the most probable source of oxygen was the crucible material, suggesting that some sort of interaction occurred between the $\mathrm{Y}_{2} \mathrm{O}_{3}$ layer of the melting crucible and the cast alloys. Evidence that the crucible $\mathrm{Y}_{2} \mathrm{O}_{3}$ wall was wetted by the molten alloy was supported by the presence of a skull of $\mathrm{TiAl}$ adherent to the crucible wall after pouring. Attempts to remove it resulted in the destruction of the crucible and the impossibility to separate the metal from the ceramic material, suggesting that some sort of melt/crucible interaction have occurred. According to its free energy of formation, $\mathrm{Y}_{2} \mathrm{O}_{3}$ is thermodynamically much more stable than titanium and aluminium oxides, thus no reaction of the crucible inner layer with the cast alloy should be expected. Thus, the most probable cause was the dissolution of the $\mathrm{Y}_{2} \mathrm{O}_{3}$ layer by the metal, which confirmed previous results of the authors [26, 27] and other researchers [35]. Moreover, the presence of small particles of $\mathrm{Y}_{2} \mathrm{O}_{3}$ dispersed in the matrix (Fig. 10) for the highest melting temperature $(1925 \mathrm{~K})$ and the presence of yttrium in every cast sample suggest that besides dissolution, erosion of the $\mathrm{Y}_{2} \mathrm{O}_{3}$ layer of the melting crucible might also have occurred.

Table 4 presents the increase in the oxygen content attributed to the melting operation itself for the different processing conditions. It was calculated by making the difference of the measured oxygen of the alloys to the theoretical maximum oxygen content of $0.16 \mathrm{wt} \%$ referred above. On Table 5, the final Y content of cast samples is presented for every processing condition.

For each temperature/superheating time combination, both oxygen and yttrium contents increase with the melting pressure, and that increase became higher as the temperature and superheating time raised [see Tables 3, 4-column (Max-Min)]. This means that the effect of the melting pressure in the alloy contamination is more evident for higher temperatures and superheating times. On the other hand, for the same chamber pressure, oxygen and yttrium concentration increased with both the melting temperature

Table 4 Oxygen enrichment during the ceramic crucible induction melting of Ti-48Al alloys for different processing conditions

\begin{tabular}{|c|c|c|c|c|c|c|c|c|c|}
\hline \multirow[t]{2}{*}{ Temperature (K) } & \multirow[t]{2}{*}{ Time (s) } & \multicolumn{8}{|c|}{ Melting pressure (mbar) } \\
\hline & & 0.005 & 0.01 & 0.05 & 0.1 & 0.15 & 0.5 & 1 & Max-Min \\
\hline & & \multicolumn{8}{|c|}{ Oxygen content (wt\%) } \\
\hline 1875 & 0 & 0.020 & 0.023 & 0.026 & 0.027 & 0.030 & 0.033 & 0.032 & 0.013 \\
\hline 1875 & 60 & 0.025 & 0.026 & 0.038 & 0.040 & 0.039 & 0.041 & 0.042 & 0.017 \\
\hline 1875 & 90 & 0.027 & 0.028 & 0.041 & 0.045 & 0.050 & 0.051 & 0.051 & 0.024 \\
\hline Difference $(90-0 \mathrm{~s})$ & & 0.007 & 0.005 & 0.015 & 0.018 & 0.020 & 0.018 & 0.019 & \\
\hline 1925 & 0 & 0.028 & 0.030 & 0.038 & 0.040 & 0.045 & 0.050 & 0.050 & 0.02 \\
\hline 1925 & 60 & 0.032 & 0.035 & 0.040 & 0.048 & 0.056 & 0.058 & 0.057 & 0.026 \\
\hline 1925 & 90 & 0.035 & 0.036 & 0.045 & 0.053 & 0.065 & 0.068 & 0.070 & 0.035 \\
\hline Difference $(90-0 \mathrm{~s})$ & & 0.007 & 0.006 & 0.007 & 0.013 & 0.020 & 0.018 & 0.020 & \\
\hline
\end{tabular}


Table 5 Final Y content of induction melted Ti-48Al alloys for different casting temperatures and superheating times, at different melting chamber pressures

\begin{tabular}{|c|c|c|c|c|c|c|c|c|c|}
\hline \multirow[t]{2}{*}{ Temperature (K) } & \multirow[t]{2}{*}{ Time (s) } & \multicolumn{8}{|c|}{ Melting pressure (mbar) } \\
\hline & & 0.005 & 0.01 & 0.05 & 0.1 & 0.15 & 0.5 & 1 & Max-Min \\
\hline & & \multicolumn{8}{|c|}{ Yttrium content (wt\%) } \\
\hline 1875 & 0 & $*$ & $*$ & $*$ & $*$ & 0.05 & 0.06 & 0.06 & 0.01 \\
\hline 1875 & 60 & $*$ & $*$ & $*$ & 0.05 & 0.05 & 0.07 & 0.06 & 0.02 \\
\hline 1875 & 90 & $*$ & $*$ & 0.05 & 0.06 & 0.06 & 0.08 & 0.08 & 0.03 \\
\hline Difference $(90-0 \mathrm{~s})$ & & - & - & - & 0.01 & 0.01 & 0.02 & 0.02 & \\
\hline 1925 & 0 & $*$ & 0.05 & 0.05 & 0.06 & 0.08 & 0.08 & 0.08 & 0.03 \\
\hline 1925 & 60 & $*$ & 0.06 & 0.06 & 0.07 & 0.09 & 0.10 & 0.11 & 0.05 \\
\hline 1925 & 90 & 0.05 & $*$ & 0.06 & 0.08 & 0.10 & 0.11 & 0.11 & 0.06 \\
\hline Difference $(90-0 \mathrm{~s})$ & & - & 0.01 & 0.01 & 0.02 & 0.02 & 0.03 & 0.03 & \\
\hline
\end{tabular}

*Below the equipment detection limit

and superheating time, with the maximum contamination $(0.070 \mathrm{wt} \% \mathrm{O}$ and $0.11 \mathrm{wt} \% \mathrm{Y})$ corresponding to the highest pressure and superheating parameters (1925 K/ $90 \mathrm{~s} / 1 \mathrm{mbar}$ ). Moreover, the highest increase occurs for the highest chamber pressures [(see Tables 3, 4-lines Difference $90-0 \mathrm{~s})]$. However, the increase in oxygen enrichment with time at constant pressure was similar for both temperatures $(\approx 0.20 \mathrm{wt} \%$ for 0.15 to $1 \mathrm{mbar}$ and $\approx 0.07 \mathrm{wt} \%$ for 0.01 and $0.005 \mathrm{mbar}$ ), and the same occurs with yttrium content. This similar behaviour of $\mathrm{Y}$ and $\mathrm{O}$ content variation strongly supports the theory that oxygen enrichment of the cast alloys was mainly due to the dissolution of the crucible yttria layer, although other sources of oxygen may also be present, like the chamber atmosphere, for example.

For the pressure range used in this work, significant changes in the thermodynamics of a possible metal-mould reaction were not expected to occur, thus other factors (which depend on the melting pressure) were responsible for the apparent increase of chemical reactivity with pressure. In Fig. 15, Al loss and oxygen enrichment were plotted as a function of melting chamber pressure for the temperature/superheating time combinations used in this work. From Fig. 15, it is evident that curves of $\mathrm{Al}$ and $\mathrm{O}$ concentration variation with the chamber pressure are almost symmetrical suggesting that some sort of relationship exists between both parameters. In fact, when the melting charge reached $\approx 1785 \mathrm{~K}$ and the first liquid became visible, as stated before, significant aluminium evaporation started, as evidenced by Al powder condensation in the furnace window. However, due to the high heating rate after reaching that temperature, when the alloys reached the superheating temperature, the aluminium content was higher than 47.25 at. $\%$ and $46.8 \mathrm{wt} \%$ for 1875 and $1925 \mathrm{~K}$, respectively (see Table 3-lines corresponding to $0 \mathrm{~s}$ superheating time). For those $\mathrm{Al}$ contents, superheating was slightly higher, but not very different, than that corresponding to a Ti-48Al alloy (100 and $150 \mathrm{~K}$ for 1875 and $1925 \mathrm{~K}$, respectively), because the difference in the alloys liquidus temperatures was quite small. However, when the isothermal stage started, the Al content started decreasing very fast with time (more for $1925 \mathrm{~K}$ ), especially for pressures below 0.01 mbar (see Table 3), causing a proportional decrease in superheating, according to the development of the liquidus line. This means that with increasing holding time and temperature, the alloys fluidity decreased, thus metal penetration and ceramic dissolution followed the same trend. This is the reason why for pressures below 0.01 mbar oxygen and yttrium enrichment were quite small (metal fluidity for the correspondent superheating was not enough to promote significant metal penetration and dissolution was the strongest and, probably, the only mechanism involved in oxygen and yttrium pickup), and was much higher for pressures above 0.15 mbar, where metal fluidity was high enough to promote metal penetration in the ceramic porosities, thus increasing the overall $\mathrm{O}$ and $\mathrm{Y}$ pickup (since those very small $\mathrm{Y}_{2} \mathrm{O}_{3}$ particles detached from the crucible inner layer were easily dissolved in the molten alloy). This was also the reason why the increase in oxygen and yttrium enrichment with time at constant pressure was similar for both temperatures [(see Tables 3, 4-lines Difference (90-0 s)]. Those alloys heated up to $1925 \mathrm{~K}$ had higher Al content than those heated up to $1875 \mathrm{~K}$ (see Table 3 ) thus, their liquidus point was higher and the superheating for the same casting temperature was similar in both alloys, thus their fluidity and ceramic penetration capability.

Although this oxygen enrichment mechanism seems the most logical one to explain the final alloys composition, other phenomena might have also contributed to the dynamics of oxygen content variation. Oxygen/oxide evaporation at the lowest chamber pressures, which is the 
Fig. 15 Variation of $\mathrm{Al}$ and $\mathrm{O}$ contents in ceramic crucible induction melted $\mathrm{Ti}-48 \mathrm{Al}$ alloys as a function of melting chamber pressure, for different temperature/superheating time combinations
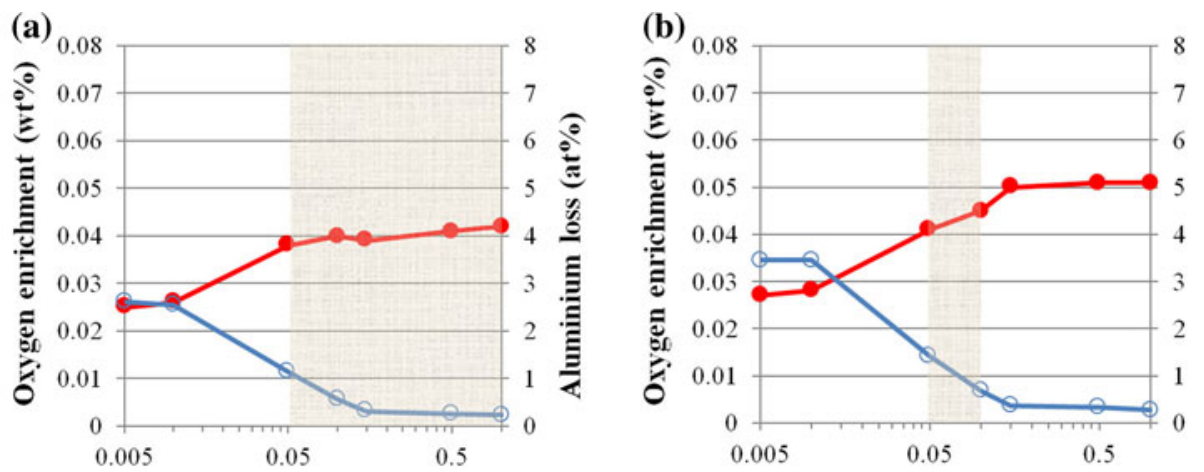

\section{$\mathrm{T}-1875 \mathrm{~K} \quad$ Chamber pressure (mbar) $\mathrm{t}-90 \mathrm{~s}$}

(d)

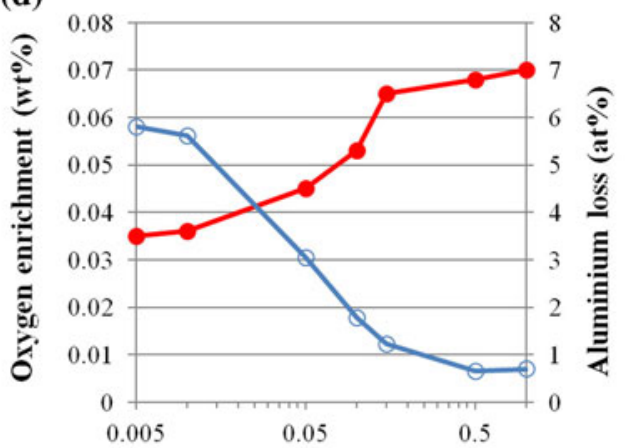

T - $1925 \mathrm{~K} \quad$ Chamber pressure (mbar)

$\mathrm{t}-90 \mathrm{~s} \quad-$ Oxygen $\prec$ Aluminium principle of oxygen removal in the high-vacuum electron beam melting process, for example, may have occurred as well, and it could explain why oxygen enrichment was quite small for pressures below 0.01 mbar.

\section{Microhardness}

Oxygen has a high embrittlement effect on TiAl alloys. On the other hand, small fluctuations in the $\mathrm{Al}$ content of binary $\mathrm{Ti}-\mathrm{Al}$ alloys in the region close to 48 at.\% $\mathrm{Al}$ also leads to significant hardness variation, which increases for $\mathrm{Al}$ values below and above 48 at.\% [32]. In Fig. 16, samples microhardness was plotted against the alloy $\mathrm{Al}$ content, and it is evident the detrimental effect of Al loss during melting. Microhardness variation with the $\mathrm{Al}$ content followed the same trend of that reported by Mitao et al. [32] for non-contaminated alloys, although microhardness values are slightly higher on this work for $\mathrm{Al}$ values between 47 and 48 at.\%, due to the presence of high oxygen contents in those alloys. For lower Al contents, microhardness values are similar to those referred by Mitao, no matter the fact of those alloys being also contaminated with oxygen (however, in lower concentration than for higher $\mathrm{Al}$ contents). This suggests that for levels of oxygen contamination below $0.20 \mathrm{wt} \%(0.16 \mathrm{wt} \%$ from

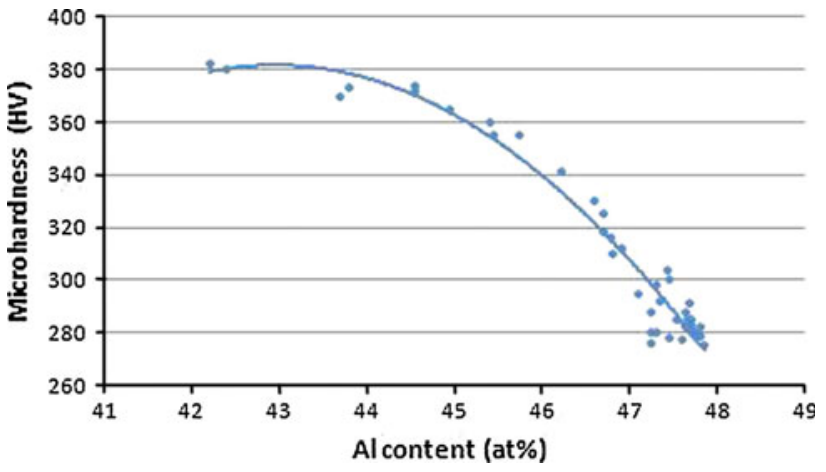

Fig. 16 Microhardness of $\mathrm{Ti}-\mathrm{Al}$ binary alloys as a function of $\mathrm{Al}$ content

the melting stock plus around $0.03 \mathrm{wt} \%$ enrichment, for those alloys with $\mathrm{Al}$ contents between 47 and 48 at.\%-see Table 4), alloys embrittlement is mainly due to the decrease in the $\mathrm{Al}$ concentration.

\section{Final remarks}

The results of this work suggest that the processing parameters of ceramic crucible induction melting of $\mathrm{Ti}-\mathrm{Al}$ alloys must be carefully selected, in order to accomplish 
the binomial $\mathrm{Al}$ evaporation/residual contamination, bearing in mind the envisaged alloy composition and the casting requirements. In TiAl-based alloys with $\mathrm{Al}$ content close to 48 at.\%, oxygen must be kept as low as possible to avoid embrittlement. Nevertheless, for many applications, oxygen contents up to $0.05 \mathrm{wt} \%$ are still accepted, since the alloys keep a minimal elongation of $0.5 \%$ and no changes in tensile strength are expected for oxygen contents below $0.1 \mathrm{wt} \%$ [38]. In what concerns to $\mathrm{Al}$ content, a decrease of 1.5 at.\% $\mathrm{Al}$ has no effect in the fracture strength of the alloy and causes an elongation decrease of about $0.1 \%$ [32].

In Fig. 15, the shadowed areas represent the processing conditions for which an oxygen enrichment of less than $0.045 \mathrm{wt} \%$ (we assume that in most industrial melting processes the oxygen content of the melting stocks is around $0.010 \mathrm{wt} \%$ ) and an $\mathrm{Al}$ loss lower than 1.5 at.\% is expected, according to the results and experimental conditions and set-up used in this work. It is evident that not every evaluated processing variables combinations can be used to produce alloys within the specification limits generally demanded for Ti-48Al-based alloys. For $1875 \mathrm{~K}$, only chamber pressures above 0.05 mbar can be used, since $60 \mathrm{~s}$ superheating time is enough to chemically homogenize the melt. However, if the holding time needs to be increased to $90 \mathrm{~s}$, for example, the allowed pressure range decreases to the interval between 0.05 and $0.1 \mathrm{mbar}$, since higher pressures will lead to oxygen pickup higher than $0.045 \mathrm{wt} \%$. Nevertheless, if a casting temperature of $1925 \mathrm{~K}$ is necessary (due to the casting geometry, for example), only $60 \mathrm{~s}$ or less holding times and chamber pressures around 0.1 mbar are tolerated. For this temperature, more than $60 \mathrm{~s}$ holding time cannot be used, since any selected chamber pressure will lead to excessive $\mathrm{Al}$ evaporation or oxygen pickup.

Although this is a theoretical lab scale approach, and the obtained results are only valid for a specific set of processing variables, a similar exercise can be done for a specific industrial plant, as far as the effects of the melting variables in the alloys compositions are known, as well as the castings requirements. This exercise will help to select the most suitable processing conditions and melting stock composition for a specific application, taking into account its alloy composition requirements and the casting geometry and dimensions.

\section{Conclusions}

The theoretical models available to preview the $\mathrm{Al}$ loss dynamics in the ISM of Ti-48Al alloys can be successfully applied to ceramic crucible induction melting. Critical and impeding $\mathrm{Al}$ evaporation pressures have been identified for different temperature/superheating time combinations and are very similar to those registered in ISM.

For the processing conditions used in this work, namely the composition, size and morphology of the melting crucible, Al loss reached 5.8 at.\% when pressures between 0.01 and 0.005 mbar were used simultaneously with $1925 \mathrm{~K}$ casting temperature and $90 \mathrm{~s}$ superheating time. The $\mathrm{Al}$ loss rate was constant for pressures below 0.01 mbar for both 1875 and $1925 \mathrm{~K}$ and above 0.5 or 0.15 for 1875 and $1925 \mathrm{~K}$, respectively.

The chamber pressure was found to indirectly affect the metal-crucible interaction and, as a consequence, the alloy contamination with oxygen and yttrium. Oxygen and yttrium pickup was mainly due to the dissolution of the $\mathrm{Y}_{2} \mathrm{O}_{3}$ crucible inner layer, either as a consequence of metal penetration in the larger pores of the crucible wall or due to erosion caused by the relative movement of the melt and the crucible wall, as a consequence of electromagnetic stirring, or, more probably, a combination of both. However, other factors like the presence of oxygen inside the melting chamber that might have promoted the formation of Ti- and Al-based oxides, and later oxygen/oxide evaporation when using the lowest chamber pressures cannot be excluded, and may have contributed to the dynamics of oxygen variation. The extent of the $\mathrm{Y}_{2} \mathrm{O}_{3}$ dissolution was found to depend on the alloy fluidity that in turn depends on the alloy $\mathrm{Al}$ content, thus the melting pressure.

For the composition, size and morphology of the melting crucible, oxygen enrichment of the cast alloys reached $0.07 \mathrm{wt} \%$ for a pressure of $1 \mathrm{mbar}, 1925 \mathrm{~K}$ casting temperature and $90 \mathrm{~s}$ superheating time, while yttrium content reached $0.11 \mathrm{wt} \%$ for the same parameters. The lowest oxygen enrichment value was $0.020 \mathrm{wt} \%$, obtained for $1875 \mathrm{~K}$ and no holding time at $0.005 \mathrm{mbar}$. For those processing conditions, the $\mathrm{Y}$ concentration was below $0.05 \mathrm{wt} \%$, which was the lowest detection limit of the EDE spectrometer.

For each evaluated temperature/time combination, an optimum pressure range was identified to simultaneously reduce the $\mathrm{Al}$ loss to a maximum of 1.5 at.\% and to limit oxygen enrichment to a maximum of $0.045 \mathrm{wt} \%$, for the processing conditions used in this work.

Acknowledgements The authors want to acknowledge to the Portuguese Foundation for Science and Technology for financially supporting this work through the research project POCI/EME/57717/ 2004 and the PhD grant SFRH/BD/32305/2006, and to the Department of Mechanical Engineering of University of Minho for the provision of research facilities.

\section{References}

1. Edwards KL (2004) Mater Des 25:529

2. Gebauer K (2006) Intermetallics 14:355

3. Sung SY, Kim YJ (2006) Intermetallics 14:1163 
4. Fu PX et al (2008) Intermetallics 16:130

5. Shiping W et al (2003) Model Simul Mater Sci Eng 11:599

6. Tetsui T (2002) Mater Sci Eng A 329-331:582

7. Cui WF, Liu CM, Bauer V, Christ HJ (2007) Intermetallics $15: 675$

8. Froes FH, Friedrich H, Kiese J, Bergoint D (2004) JOM 56(2):40

9. Norris G (2006) Flight International (electronic version), June 2006

10. Froes FH, Gungor M, Imam MA (2007) JOM 59(6):28

11. Imayev RM, Imayev VM, Oehring M, Appel F (2007) Intermetallics 15:451

12. Jovanovic MT, Dimicic B, Bobic I, Zec S, Maksimovic V (2005) J Mater Process Technol 167:14

13. Liu $\mathrm{K}$ et al (2005) Intermetallics 11:925

14. Sung S-Y, Kim Y-J (2006) Intermetallics 14:1163

15. Mi J, Harding RA, Wickins M, Campbell J (2003) Intermetallics $11: 377$

16. Harding RA, Wickins M (2003) Mater Sci Technol 19:1235

17. Frueh C et al (1996) Int J Cast Met Res 9(4):233

18. Liu A et al (2008) Rare Met Mater Eng 37(6):956

19. Gomes F, Barbosa J, Ribeiro CS (2008) Intermetallics 16:1292

20. Liu K et al (2005) Intermetallics 13:925

21. Sato T, Yoneda Y, Matsumoto N (1992) Trans Jpn Foundrym Soc 11:27

22. Kartavykh AV, Tcherdyntsev VV, Zollinger J (2010) Mater Chem Phys 119:347

23. Kartavykh AV, Tcherdyntsev VV, Zollinger J (2009) Mater Chem Phys 116:300
24. Barbosa J, Ribeiro CS, Monteiro AC (2006) Portuguese Patent PT103018

25. Barbosa J, Ribeiro CS, Monteiro AC (2006) International Patent Pending WO2005/025778 A1

26. Barbosa J, Ribeiro CS, Monteiro AC (2007) Intermetallics 15:845

27. Barbosa J et al (2006) Int J Cast Met Res 19(6):331

28. Schadlich-Stubenrauch J, Dieckhues GW, Sahm PR (1994) 27th Dedicated conference on new and alternative materials for the transportation industry, Aachen, Germany

29. Jia Q, Cui YY, Yang R (2006) J Mater Sci 41:3045. doi: 10.1007/s10853-006-6785-3

30. Yanqing S et al (2002) J Alloys Compd 334:261

31. Jingjie G et al (2002) Metall Mater Trans A 33:3249

32. Mitao S, Tsuyama S, Minakawa K (1991) Mater Sci Eng A 143:51

33. Takeyama M, Kumagai T, Nakamura M, Kikuchi M (1993) Struct Intermetall 1993:167

34. Okamoto H (1996) Binary alloys phase diagrams-aluminiumtitanium system, CD-Rom 2nd edn. ASM International

35. Kuang JP, Harding RA, Campbell J (2001) Int J Cast Met Res 13(4): 277

36. Renjie C, Ming G, Zhang H, Shengkai G (2010) J Mater Process Technol 210:1190

37. Bellot JP, Ablitzer D, Hess E (2000) Metall Mater Trans B 31(4):845

38. Sakamoto K, Yoshikawa K, Kusamichi T, Onoye T (1992) ISIJ Int 32(5):616

39. Hadi M (2009) Russ J Non-Ferr Met 50(1):24 